technique represents other possibility, besides pelvic exenteration for tumors located laterally.

Methodology Video presentation of laterally extened endopelvic resection in patient with cervical cancer recurrence after radiotherapy localized laterally in the left obturator fossa and residual parametria and paracolpium with complete obstruction of ureter and afunctional left kidney.

Result(s)* Recurrent tumor was removed in toto with resection of internal iliac vessel, residual parametria and paracolpium and complet resestion of infiltrated ureter.

Conclusion* Technique of laterally extended endopelvic resection allows - due to precise knowledge of pelvic structures and their topography - for safe removal of even laterally located tumor deep in the pelvis/pevic floor.

\section{INDOCYANINE GREEN TO ASSESS VASCULARITY OF BRICKER ILEAL CONDUIT ANASTOMOSIS DURING PELVIC EXENTERATION FOR RECURRENT CERVICAL CANCER}

${ }^{1} \mathrm{~N}$ Bizzarri ${ }^{*},{ }^{2} \mathrm{~N}$ Foschi, ${ }^{1} \mathrm{M}$ Loverro, ${ }^{1} \mathrm{~L}$ Tortorella, ${ }^{3} \mathrm{~F}$ Santullo, ${ }^{1} \mathrm{~A}$ Rosati, ${ }^{1} \mathrm{~S}$ Gueli Alletti, ${ }^{1} \mathrm{~B}$ Costantini, 'V Gallotta, 'MG Ferrandina, ' ${ }^{1} \mathrm{~A}$ Fagotti, ${ }^{1} \mathrm{~F}$ Fanfani, ' $\mathrm{G}$ Scambia, $1,4 \mathrm{G}$ Vizzielli. ${ }^{1}$ Fondazione Policlinico Universitario A. Gemelli, IRCCS, UOC Ginecologia Oncologica, Dipartimento per la salute della Donna e del Bambino e della Salute Pubblica, Rome, Italy; ${ }^{2}$ Fondazione Policlinico Universitario A. Gemelli, IRCCS, UOC Clinica Urologica, Rome, Italy; ${ }^{3}$ Fondazione Policlinico Universitario A. Gemelli, IRCCS, UOC Chirurgia Peritoneo e Retroperitoneo, Rome, Italy; ${ }^{4}$ Academic Hospital of Udine, Obstetrics and Gynecology Department, Udine, Italy

\subsection{6/ijgc-2021-ESGO.72}

Introduction/Background* Pelvic exenteration performed for recurrent cervical cancer has been associated to urological short- and long-term morbidity, due to altered vascularization of tissues for previous radiotherapy. The aim of the present video is to demonstrate the use of intravenous indocyanine green (ICG) to assess vascularity of Bicker ileal conduit after pelvic exenteration for recurrent cervical cancer and to evaluate the feasibility and safety of this technique.

Methodology The patient was a 64-year-old woman who underwent exclusive chemoradiation for FIGO stage IIB cervical SCC. Seven months after the end of the radiotherapy she was diagnosed with an isolated central pelvic recurrence involving bladder wall. The patient underwent open total pelvic exenteration with Bricker ileal conduit urinary diversion and end sigmoid colostomy. After performing the anastomoses, the perfusion of tissues was analyzed with intravenous injection of $3 \mathrm{ml}$ of ICG and a $(1.25 \mathrm{mg} / \mathrm{ml})$ and a near infra-red SPY Portable Handheld Imager (SPY-PHI) (Stryker, Kalamazoo, Michigan, US). After ICG injection, a four-tier $(+++$ versus ++ - versus +- versus - ) classification was used to assess the vascularity of each anastomosis: ileum-ileum, right and left ureter with small bowel. The classification of ICG perfusion of anastomoses was independently performed by the urologist and the gynecologic oncologist.

Result(s)* Intravenous injection did not cause any adverse event. After ICG injection, the left ureter-ileal conduit demonstrated sub-optimal vascularization (-), the right ureter-ileal conduit and the ileum-ileum showed optimal vascularization $(+++)$. ICG perfusion is demonstrated with three different modalities: Overlay Fluorescence Mode, Color Segmented Fluorescence Mode, Contrast Fluorescence Mode. Patient developed benign left ureteric stricture which was diagnosed with a CT-scan 45 days after the radical surgery and was treated with anterograde ureteric stenting.
Conclusion* The use of ICG to intra-operatively assess the anastomoses perfusion at time of pelvic exenteration for gynecologic malignancy is a feasible and safe technique. The different vascularization of anastomotic stumps may be related to anatomical sites and to previous radiation treatment and it may be useful to predict post-operative complications. This approach could be of support in selecting patients at higher risk of complications, who may need personalized follow up.

\section{SURGICAL LYMPH NODE STAGING IN LOCALLY ADVANCED CERVICAL CARCINOMA}

${ }^{1} \mathrm{M}$ Imterat* ${ }^{*}{ }^{1} \mathrm{M}$ Moubarak, ${ }^{2} \mathrm{KU}$ Waltering, ${ }^{3} \mathrm{~K}$ Berkovic, ${ }^{3} \mathrm{I}$ Stöver, ${ }^{3} \mathrm{~A}$ Koziorowski, ${ }^{1,4}$ B Ataseven, ${ }^{1} \mathrm{P}$ Harter, ${ }^{1} \mathrm{~A}$ Du Bois, ${ }^{1} \mathrm{~N}$ Concin. ${ }^{1}$ Ev. Kliniken Essen-Mitte, Department of Gynecology and Gynecologic Oncology, Essen, Germany; ${ }^{2}$ Ev. Kliniken Essen-Mitte, Department of Radiology, Essen, Germany; ${ }^{3}$ Ev. Kliniken Essen-Mitte, Department of Radiotherapy, Essen, Germany; ${ }^{4}$ University Hospital, LMU Munich, Department of Obstetrics and Gynecology, Munich, Germany

\subsection{6/ijgc-2021-ESG0.73}

Introduction/Background* Radiation field planning in patients with locally advanced cervical cancer (LACC) undergoing primary definitive chemoradiotherapy is influenced by lymph

Abstract 854 Table 1 Patients demographic and tumor characteristics according to pathological (pelvic and paraaortic) lymph-node status

\begin{tabular}{|c|c|c|c|c|}
\hline Characteristics & $\begin{array}{l}\text { Negative } \\
\text { Lymph-node } \\
\mathrm{N}=14(24.1 \%)\end{array}$ & $\begin{array}{l}\text { Positive } \\
\text { lymph-node } \\
\mathrm{N}=44(75.9 \%)\end{array}$ & $\begin{array}{l}\text { Entire } \\
\text { cohort } \\
\mathrm{N}=58\end{array}$ & p-value \\
\hline $\begin{array}{l}\text { Patient age, years, } \\
\text { median (Range) }\end{array}$ & $59.5(32-72)$ & $51(26-80)$ & $53(26-80)$ & 0.228 \\
\hline ECOG* score: & $13(92.9)$ & $41(93.2)$ & $54(93.1)$ & 1.000 \\
\hline 0 & $1(7.1)$ & $3(6.8)$ & $4(6.9)$ & \\
\hline \multicolumn{5}{|l|}{$>0$} \\
\hline \multicolumn{5}{|c|}{ Preoperative imaging technique: } \\
\hline CT & $14(100)$ & $42(95.5)$ & 56 (96.6) & $0.417(\mathrm{CT})$ \\
\hline MRI & $11(78.6)$ & $40(90.9)$ & $51(87.9)$ & 0.217 (MRI) \\
\hline Histological type: & $13(92.9)$ & $39(88.6)$ & $52(89.7)$ & 0.719 \\
\hline squamous cell & $1(7.1)$ & $3(6.8)$ & $4(6.9)$ & \\
\hline $\begin{array}{l}\text { sdenocarcinoma small } \\
\text { cell }\end{array}$ & 0 & $2(4.5)$ & $2(3.4)$ & \\
\hline Grading: & $6(42.9)$ & $15(34.1)$ & $21(36.2)$ & 0.799 \\
\hline G2 & $7(50)$ & $24(54.5)$ & $31(53.4)$ & \\
\hline G3 & $1(7.1)$ & $5(11.4)$ & $6(10.3)$ & \\
\hline \multicolumn{5}{|l|}{$\mathrm{GX}$} \\
\hline cT classification: & 0 & $12(27.3)$ & $12(20.7)$ & 0.004 \\
\hline 1b1 & 0 & $2(4.5)$ & $2(3.4)$ & \\
\hline $1 \mathrm{~b} 2$ & 0 & $2(4.5)$ & $2(3.4)$ & \\
\hline $2 a 1$ & $1(7.1)$ & 7 (15.9) & $8(13.8)$ & \\
\hline $2 \mathrm{a} 2$ & $7(50)$ & $11(25)$ & $18(31)$ & \\
\hline $2 b$ & 0 & $3(6.8)$ & $3(5.2)$ & \\
\hline 3a & $1(7.1)$ & 6 (13.6) & $7(12.1)$ & \\
\hline $3 b$ & $5(35.7)$ & $1(2.3)$ & $6(10.3)$ & \\
\hline \multicolumn{5}{|l|}{$4 a$} \\
\hline Lymph-node site: & 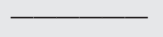 & $26(59.1)$ & $26(44.8)$ & \\
\hline pelvic paraaortal pelvic & & $6(13.6)$ & $6(10.3)$ & \\
\hline +paraaortal & & $12(27.3)$ & $12(20.7)$ & \\
\hline
\end{tabular}

Data are presented as $\mathrm{n}(\%)$; Significance was measured using Chi squared * Eastern Cooperative Oncology Group 